\title{
Infección por adenovirus en hospital de niños con enfermedades respiratorias crónicas
}

\author{
CARLOS FLORES B. ${ }^{1}$, MIREYA MÉNDEZ R. ${ }^{2}$, CLAUDIA ASTUDILLO M. ${ }^{2}$, \\ HUGO CERDA B. ${ }^{2}$, TATIANA ESPINOZA P. ${ }^{2}$, SOLEDAD MONTES F. ${ }^{2}$, \\ SANDRA FLORES O. ${ }^{3}$, BERNARDITA CHATEAU I. ${ }^{2}$ \\ Hospital Josefina Martínez de Ferrari, División de Pediatría, Facultad de Medicina, Pontificia Universidad Católica de Chile. \\ 1. Becado Enfermedades Respiratorias del Niño, Pontificia Universidad Católica de Chile. \\ 2. Broncopulmonar Infantil, Hospital Josefina Martínez de Ferrari. \\ 3. Interna de Medicina, Universidad Andrés Bello.
}

\begin{abstract}
Adenovirus infection in a children's hospital with chronic pulmonary diseases

Introduction: Intrahospital adenovirus infections spread rapidly in closed environments causing outbreaks associated with high morbidity and mortality. Objectives: To identify the attack rate (AR) of adenovirus in a hospital treating children with Chronic Respiratory Diseases (CRD) and to evaluate associated factors that facilitate infection. Patients and Methods: Fifty children with CRD were evaluated between June 2010 and October 2010 at Josefina Martinez Hospital. They were exposed to patients with acute lower respiratory infection during winter. Patients with CRD symptoms (fever and change in basal nasal mucus) underwent Viral Direct Immunofluorescence (DIF). The case was defined as "symptomatic patient with positive DIF for Adenovirus". Primary, secondary and global ARs were evaluated. Variables such as gender, age, tracheostomy and gastrostomy were analyzed looking for associations with the cases. Results: $44 \%$ of patients were infants; $68 \%$ of children had tracheostomy and $54 \%$ had gastrostomy. The first patient with Adenovirus was admitted in June and the primary case was reported two weeks later. 25 cases presented secondary AR corresponding to $51 \%$. Global AR was $52 \%$ overall. No mortality was reported. The risk was three times higher in infants than older children (OR 3.31 [IC95\% 1.02-10.72; $\mathrm{p}=0.046]$ ). No significant associations with tracheostomy, gastrostomy and gender were found. Conclusions: The rapid spread of adenovirus infection in closed environments requires extreme prevention measures especially regarding infants.

(Key words: Adenovirus, hospital outbreak, chronic respiratory disease, children).

Rev Chil Pediatr 2013; 84 (5): 522-526
\end{abstract}

\section{RESUMEN}

Introducción: Las infecciones por adenovirus se diseminan rápidamente en recintos cerrados causando brotes asociados a gran morbimortalidad. Objetivos: Identificar tasa de ataque (TA) de infección por adenovirus en

Recibido el 5 de febrero de 2012, devuelto para corregir el 9 de abril de 2012, segunda versión 22 de marzo de 2013, aceptado para publicación el 22 de julio de 2013.

Este trabajo cumple con los requisitos sobre consentimiento /asentimiento informado, comité de ética, financiamiento, estudios animales y sobre la ausencia de conflictos de intereses según corresponda.

Correspondencia a:

Dr. Carlos Flores Berríos

E-mail: ceflowers@gmail.com 
hospital de niños con enfermedades respiratorias crónicas (ERC) y evaluar factores asociados que faciliten la infección. Pacientes y Método: Entre junio y octubre de 2010 se evaluaron 50 niños con ERC del Hospital Josefina Martínez. Ellos estuvieron expuestos durante el invierno a pacientes con infección respiratoria aguda baja. A los pacientes con ERC sintomáticos (fiebre y cambio en su signología respiratoria basal) se les realizó Inmunofluorescencia Directa (IFD) Viral. "Caso" fue definido como "paciente sintomático e IFD positiva para Adenovirus". Se evaluaron TA primaria, secundaria y global. Variables como género, edad, traqueostomía y gastrostomía fueron analizadas buscando asociación con los casos. Resultados: El 44\% de los pacientes eran lactantes. El 68\% tenía traqueostomía y 54\% gastrostomía. El primer paciente con Adenovirus ingresó en junio y el caso primario apareció dos semanas después. Hubo 25 casos secundarios que representaron TA secundaria de $51 \%$. La TA global fue 52\%. No hubo fallecidos. Los lactantes tuvieron un riesgo tres veces mayor que los niños mayores de contraer la infección (OR 3,31 [IC95\% 1,02-10,72; p = 0,046]). No hubo asociación significativa con traqueostomía, gastrostomía ni género. Conclusiones: La alta diseminación de la infección por adenovirus en recintos cerrados obliga a extremar las medidas de prevención de IAAS especialmente en lactantes. (Palabras clave: Adenovirus, brote intrahospitalario, enfermedad respiratoria crónica, niños).

Rev Chil Pediatr 2013; 84 (5): 522-526

\section{Introducción}

Las infecciones respiratorias agudas bajas constituyen una importante causa de muerte en menores de 5 años, sobretodo en países en desarrollo ${ }^{1}$. En los niños menores de dos años, el 70 a $90 \%$ son de causa viral y del total de estas infecciones, el 2 a 5\% corresponde a Adenovirus, cuya importancia está dada por la alta mortalidad vinculada fundamentalmente a brotes intrahospitalarios ${ }^{2}$. El Adenovirus es responsable de infecciones endémicas durante todo el año ${ }^{3}$. La mayoría de las infecciones son leves a moderadas con curso benigno y autolimitadas, pero también existen casos graves que pueden llevar a la muerte o dejar serias secuelas ${ }^{2,4}$. La transmisión es de persona a persona a través del contacto con secreciones respiratorias, transmisión fecal-oral, aerosoles y vía fomites. Estudios epidemiológicos de enfermedades respiratorias bajas, en que los niños requieren hospitalización en Chile, han detectado al virus respiratorio sincicial en un $50 \%$ y al adenovirus en un $12,6 \%$ de los $\operatorname{casos}^{5,6}$.

Las infecciones por adenovirus asociadas a atención de salud ocurren por incumplimiento de las normas de control de infecciones intrahospitalarias como las medidas de aislamiento, el lavado de manos o por la inapropiada limpieza de los utensilios o instrumentos médicos que se utilizan en la atención del paciente ${ }^{7}$. Este tipo de infección ha sido descrita de curso más severo que las adquiridas en la comunidad ${ }^{8,9}$.
En Chile se reportó una tasa de ataque de 55\% entre niños hospitalizados por patología respiratoria baja en el Hospital Roberto del Río entre mayo de 1995 y octubre de $1996^{10}$. Luego, la sola medida de ingreso sistemático de los pacientes a salas individuales redujo significativamente la infección nosocomial entre 1996 y $1998^{11}$. En un estudio realizado en el Hospital Exequiel González Cortés, durante el año 2004, se observó una tasa de ataque de 16,5\% y se identificó que, edad entre 4 y 10 meses, tener enfermedad subyacente y adquirir el adenovirus durante un brote intrahospitalario, eran factores de riesgo de enfermedad grave ${ }^{12}$.

El Hospital Josefina Martínez es un establecimiento que mantiene internados, por largo período de tiempo, a niños con necesidades especiales que padecen ERC y que, durante el invierno, habilita cuatro salas para recibir en forma transitoria a niños con patología respiratoria aguda que requieran manejo de cuidados intermedios. Previo a la implementación de la Campaña de Invierno, se capacitó al personal en la prevención de infecciones asociadas a atención de salud (IAAS) y se establecieron criterios de ingreso muy estrictos para la recepción de estos pacientes. Sin embargo, a pesar de estas medidas, el establecimiento se vio enfrentado a un brote epidémico intrahospitalario por adenovirus. Dadas las características de los pacientes con ERC por su enfermedad de base y apoyados en la literatura en que se establece que esta condición es un factor de riesgo que 
determina la evolución de las IAAS ${ }^{12}$ se planteó como hipótesis que aquéllos con traqueostomía y/o gastrostomía serían más vulnerables a la infección y se definió como objetivos evaluar la tasa de ataque, la mortalidad y los factores de riesgo asociados a ella.

\section{Pacientes y Método}

Estudio retrospectivo observacional que evaluó a los 50 pacientes pediátricos que se encontraban hospitalizados en el Hospital Josefina Martínez de la comuna de Puente Alto de Santiago entre el 1 de junio y 31 de octubre de 2010. Ellos padecen de ERC y tienen necesidades especiales. La mayoría de estos pacientes permanecen internados por largos períodos hasta tener la posibilidad de ser atendidos en domicilio, con oxígeno y/o ventilación mecánica. Este establecimiento es uno de los pocos en Chile que reúne a este tipo de pacientes, otorgándoles un tratamiento multidisciplinario. Durante este período, estuvieron expuestos a pacientes con patología respiratoria aguda que ingresaron durante la Campaña de Invierno como una forma de apoyar a la red asistencial colapsada por la enorme demanda de hospitalizaciones que se genera. Se destinaron cuatro salas exclusivas para esto, de seis cupos cada una, para recibir a los ingresos que eran coordinados por una mesa central que respondía a las solicitudes de los distintos centros hospitalarios de Santiago. Se estableció una exigente vigilancia epidemiológica de los pacientes agudos y crónicos. Todos los ingresos de pacientes agudos eran sometidos a inmunofluorescencia directa viral de aspirados nasofaríngeos. Ante la aparición del primer caso positivo de adenovirus se implementaron las medidas de aislamiento establecidas y se vigiló a los pacientes con ERC en forma permanente. Se realizó estudio de la curva epidémica de la difusión de la enfermedad entre los niños con necesidades especiales definiendo "caso" como aquel paciente con enfermedad respiratoria crónica que presenta fiebre, disnea, cambio en las características de las secreciones traqueobronquiales basales o aumento de los requerimientos de oxígeno y cuya inmunofluorescencia directa viral sea positiva para adenovirus.
Se evaluaron variables como sexo, edad, traqueostomía y gastrostomía buscando asociación con la infección por adenovirus. Se analizó mortalidad general y tasa de ataque primaria, secundaria y global. Se utilizó programa estadístico SPSS versión 15 y se realizó análisis descriptivo, tablas de contingencia y estudio de regresión logística.

\section{Resultados}

Se evaluaron los 50 pacientes internados en el Hospital Josefina Martínez con diagnóstico de alguna enfermedad respiratoria crónica (tabla 1). El $46 \%$ de los pacientes eran de sexo masculino y el $54 \%$ de sexo femenino. El $44 \%$ de ellos eran menores de 2 años, el 40\% tenía entre 2 a 5 años y el 16\% eran de 6 años y más (tabla 2). El 68\% tenían traqueostomía y el 54\% se alimentaba a través de gastrostomía.

El primer paciente con patología respiratoria aguda con inmunofluorescencia directa positiva para adenovirus ingresó en el mes de junio. A las dos semanas apareció el primer caso entre los pacientes crónicos representando una TA primaria del $2 \%$. Dos meses después del caso índice, el $20 \%$ de los pacientes con enfermedad respiratoria crónica estaba infectado y a los cuatro meses la TA secundaria fue del 51\% (figura 1). La mayor incidencia ocurrió durante el mes de septiembre, con 15 casos detectados. El último caso se notificó en octubre, llegando a un total de 26 IAAS en cuatro meses de vigilancia lo que representó una TA global de 52\%. No hubo pacientes fallecidos y no se han registrado, hasta el momento del estudio, secuelas entre los afectados.

Al analizar los factores de riesgo asociados

Tabla 1. Distribución de pacientes crónicos según patología

\begin{tabular}{|lcc|}
\hline Diagnóstico & $\begin{array}{c}\text { Frecuencia } \\
\text { (n) }\end{array}$ & $\begin{array}{c}\text { Porcentaje } \\
\text { (\%) }\end{array}$ \\
\hline Daño pulmonar crónico & 25 & 50 \\
\hline Alteración de vía aérea* & 13 & 26 \\
\hline Enfermedad neuromuscular & 11 & 22 \\
\hline Agenesia parcial diafragma & 1 & 2 \\
\hline Total & 50 & 100 \\
\hline
\end{tabular}

*Congénita o adquirida. 
Tabla 2. Distribución de pacientes crónicos según edad

\begin{tabular}{|lcc|}
\hline Rango etario & $\begin{array}{c}\text { Frecuencia } \\
\text { (n) }\end{array}$ & $\begin{array}{c}\text { Porcentaje } \\
\text { (\%) }\end{array}$ \\
\hline 0 a 23 meses & 22 & 44 \\
2 a 5 años & 20 & 40 \\
6 y más años & 8 & 16 \\
Total & 50 & 100 \\
\hline
\end{tabular}

Tabla 3. Factores de riesgo asociados a brote epidémico intrahospitalario por adenovirus

\begin{tabular}{|lccc|}
\hline Variables en estudio & OR & IC $\mathbf{9 5 \%}$ & Valor $\mathbf{p}$ \\
\hline Edad 0 a 23 meses* & 3,31 & $1,02-10,72$ & $0,046^{* *}$ \\
\hline Género masculino** & 1,01 & $0,33-3,08$ & 0,982 \\
\hline Traqueostomía & 1,13 & $0,34-3,70$ & 0,846 \\
\hline Gastrostomía & 1,36 & $0,45-4,16$ & 0,586 \\
\hline
\end{tabular}

*En relación a pacientes mayores de 2 años. **En relación a pacientes de género femenino.

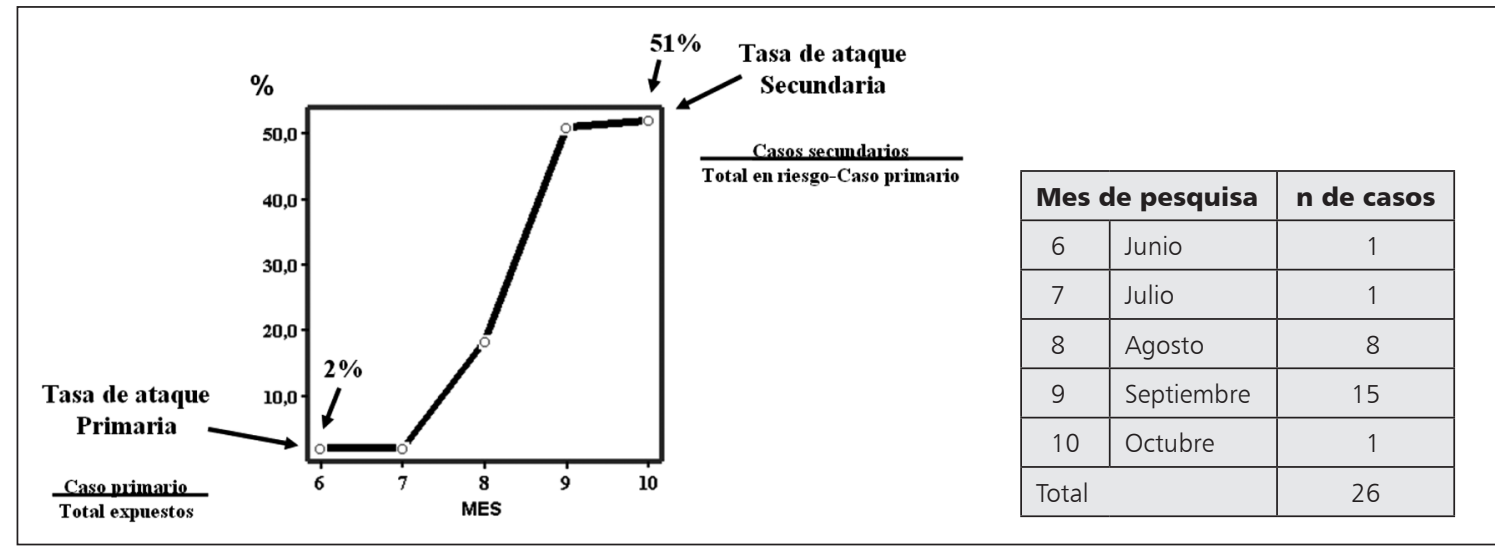

Figura 1. Tasa de ataque de infección respiratoria por adenovirus en pacientes con ERC.

a la IAAS se logró demostrar que el grupo de lactantes tuvieron un riesgo mayor a tres veces de contraerla en relación a los niños de 2 años de edad o más (OR 3,31 [IC 95\% 1,02$10,72 ; \mathrm{p}=0,046])$. La TA global de los lactantes fue de $68,2 \%$ y en los mayores de 2 años de 39,3\%. Las variables género, traqueostomía y gastrostomía no resultaron estar asociadas significativamente con la infección por adenovirus (tabla 3 ).

\section{Discusión}

Las infecciones por adenovirus son de fácil diseminación y pueden tener secuelas graves. Los recintos cerrados son lugares aptos para el rápido contagio de este virus, estableciendo un comportamiento en brote, que está bien descrito en adenovirus ${ }^{2-4,6-11}$. El Hospital Josefina Martínez, al ser un recinto para niños con necesidades especiales y enfermedades respiratorias crónicas, es de alto riesgo para este tipo de brote, aunque no existen estudios en esta situación específica. Los pacientes traqueostomizados y/o conectados a ventilación mecánica, al tener fácil acceso a la vía aérea, sumado a la instrumentalización frecuente, serían más vulnerables a las IAAS. En este estudio, sin embargo, la condición de tener traqueostomía no demostró ser factor de riesgo para el contagio, pero la edad, que al igual que en investigaciones previas, sigue apareciendo como un factor de riesgo importante en este tipo de infecciones ${ }^{13,14}$.

La diseminación de la infección por adenovirus es alta y prolongada en el tiempo y se justifica extender las medidas preventivas de IAAS en especial en recintos cerrados y de largas estadías de sus pacientes. En este estudio, desde el caso primario detectado en junio, se sumaron 25 casos secundarios hasta el mes de octubre, siendo un período prolongado de exposición, con una curva ascendente que demuestra la alta transmisibilidad. La tasa de ata- 
que secundaria y la tasa de ataque global fueron muy similares, 51 y $52 \%$ respectivamente. Importante limitante en la vigilancia fue no detectar oportunamente a los funcionarios que quebrantaban las normas de prevención de IAAS, aunque los mismos pacientes que se desplazaban libremente por el establecimiento probablemente cumplieron un rol no identificado en este brote. Es necesario implementar en las futuras campañas estudios prospectivos que permitan tener un rol más activo por parte de los equipos de salud.

La mayor parte de los estudios revisados se han realizado en recintos hospitalarios donde los niños permanecen un promedio de días de hospitalización bastante menor que el tiempo que permanecen los pacientes del Hospital Josefina Martínez quienes se ven expuestos a la excreción prolongada del virus en el ambiente intrahospitalario.

Existen más de cincuenta serotipos de adenovirus y cada uno de ellos condiciona una situación clínica distinta. Este estudio tiene la limitante de no haber tenido la posibilidad de serotipificar al adenovirus involucrado en este brote, pero por la evolución de los pacientes no fue de los más agresivos como aquéllos de los años 90 en Chile ${ }^{10}$.

En conclusión, se ha descrito una rápida evolución de un brote epidémico por adenovirus en un recinto hospitalario que atiende en forma multidisciplinaria a niños con ERC con necesidades especiales, muchos de los cuales fueron previamente sometidos a traqueostomía y gastrostomía para mejorar su condición y que permanecen largos períodos de hospitalización. A pesar de la alta tasa de ataque secundaria de la infección por adenovirus no hubo fallecidos. Medidas de prevención de IAAS deben ser constantes y mantenidas en el tiempo especialmente con este agente. La detección precoz y el manejo en cohortes sobretodo en lactantes permitirán un mejor manejo de este tipo de brotes. Como factores de riesgo asociado a la infección sólo tuvo significancia estadística la edad menor a dos años. Condiciones como traqueostomía y gastrostomía no demostraron ser significativas.

\section{Referencias}

1.- OPS OMS: Boletín AIEPI N ${ }^{\circ}$ 4. Washington: OPS 2000.

2.- Dalmás S, Pereyra ML, Pírez MC, et al: Infección respiratoria aguda baja por adenovirus en niños hospitalizados menores de dos años. Arch Pediatr Urug 2003; 74: 15-21.

3.- Larrañaga C, Kajon A, Villagra, et al: Adenovirus surveillance on children hospitalized for acute lower respiratory infections in Chile. J Med Virol 2000; 60: 342-6.

4.- Langley JM: Adenoviruses. Pediatrics in Review. 2005; 26: 244-9.

5.- Girardi G, Astudillo P, Zúniga F: El programa IRA en Chile: hitos e historia. Rev Chil Pediatr 2001; 72: 292300 .

6.- Palomino MA, Larrañaga C, Villagra E, Camacho $J$, Avendaño L: Adenovirus and respiratory syncytial virus-adenovirus mixed acute lower respiratory infections in Chilean infants. Pediatr Infect Dis J 2004; 23 : $337-41$

7.- Bhumbra N, Wroblewski ME: Adenovirus. Pediatrics in review 2010; 31: 173-4.

8.- Barrios P, Le Pera V, Icardi A, et al: Infecciones intrahospitalarias por adenovirus em niños asistidos en el Centro Hospitalario Pereira Rossell, 2001-2006. Rev Med Urug 2009; 25: 102-9.

9.- Moon R: Adenovirus Infections. Pediatrics in Review 1999; 20: 56.

10.- Palomino MA, Larrañaga $C$, Avendaño LF: Hospitalacquired adenovirus $7 \mathrm{~h}$ infantile respiratory infection in Chile. Pediatr Infect Dis J 2000; 19: 527-31.

11.- Topelberg $S$, Chevarría $C$ : Control de transmission intrahospitalaria de Adenovirus implementando ingresos en aislamiento individual. Y ¿por qué hacerlo? Rev Ped Elec [en línea] 2005, Vol 2, N³. ISSN 0718-0918.

12.- Pérez MJ, Kogan R, Maggi L, Mendoza C: Seguimiento clínico y factores de riesgo en niños con enfermedades respiratorias por adenovirus. Rev Chil Pediatr 2007; 78 : 261-7.

13.- Kojaoghlanian T, Flomenberg P, Horwitz M: The impact of adenovirus infection on the immunocompromised host. Rev Med Virol 2003; 13: 155-71.

14.- Murtagh P, Giubergia V, Viale D, Bauer G, González H: Lower respiratory infections by adenovirus in children. Clinical Features and risk factors for bronchiolitis obliterans and mortality. Pediatric Pulmonology 2009; 44: 450-6. 